\title{
Analisa Pengukuran Cylinder Liner dan Piston pada Overhoul Diesel Engine
}

\author{
Lilin Hermawati $^{1}$, Iman Mujiarto ${ }^{2}$, Kundori ${ }^{3}$, Sugeng Hariyadi ${ }^{4}$ \\ ${ }^{1,2,3,4}$ Program studi Teknika, Fakultas Kemaritiman Universitas Maritim Amni Semarang \\ Email: ${ }^{1}$ linhermawati80@gmail.com, ${ }^{2}$ imnmu@yahoo.com, ${ }^{3}$ kundori.jaken@ gmail.com, \\ ${ }^{4}$ sugengharyadi03@gmail.com
}

\begin{abstract}
ABSTRAK
Selain mengetahui berbagai jenis komponen-komponen permesinan yang ada, operator dituntut harus mengetahui perawatan dan mampu melakukan pengukuran setiap komponen agar kinerja diesel engine tidak mengalami kendala yang megakibatkan performa mesin menurun. Sedang komponen penunjang kerja diesel engine adalah seperti cylinder liner, karena komponen cylinder liner menentukan besar volume silinder dan kinerja diesel engine. Bentuk dari Cylinder liner seperti tabung dimana proses pembuatannya menggunakan proses horizontal centrifugal casting. Proses Horizontal Centrifugal casting merupakan proses pengecoran pembuatan cylinder liner dengan cara menuangkan logam cair ke dalam cetakan yang berputar. Pelaksanaan Top Overhaul pada Mesin diesel dilaksanakan dengan cara membuka bagian cylinder head atau bagian atas mesin. Bagian yang diperiksa antara lain rocker arm, inlet dan exhaust valve, injektor, air starting valve dan push rod. Top Overhaul dilaksanakan saat jam kerja mesin diesel sudah bekerja dengan jam kerja selama sekitar 6.000 jam. Perawatan Major Overhaul, yang meliputi pemeriksaan, perawatan dan pemeriksaan yang dilakukan pada seluruh pekerjaan Top Overhaul dan bagian piston, connecting rod, ring piston, metal duduk dan metal jalan. Perawatan Major Overhaul dilaksanakan pada waktu mesin diesel memiliki jam kerja 12000 jam sesuai dengan Diesel Engine Intruction Book. Bagian Cylinder liner sering terjadi kerusakan atau kelonggaran yang biasa disebut dengan abrasi, erosi dan korosi. Maka dalam cylinder liner harus ada perawatan dan pengukuran dengan mempergunakan alat inside micrometer. Dari hasil pengukuran dan perawatan pada cylinder liner didapatkan perhitungan keovalan, ketirusan dan juga keausan, untuk mengetahui spesifikasi atau melampui limit yang sudah ditentukan dalam Main Engine Intruction Book yang terdapat diatas kapal.
\end{abstract}

Kata kunci: Perawatan, Cylinder Liner, Piston, Overhaul, Mesin Diesel

\section{ABSTRACT}

In addition to knowing the various types of machining components that exist, operators are required to know the maintenance and be able to measure each component so that the diesel engine's performance does not experience problems that result in decreased engine performance. Meanwhile, the supporting components of the diesel engine are like cylinder liners, because the cylinder liner components determine the volume of the cylinder and the performance of the diesel engine. The shape of the cylinder liner is like a tube where the manufacturing process uses a horizontal centrifugal casting process. Horizontal Centrifugal casting process is a casting process for making cylinder liners by pouring molten metal into a rotating mold. Implementation of Top Overhaul on diesel engines is carried out by opening the cylinder head or the top of the engine. The parts examined include the rocker arm, inlet and exhaust valves, injectors, air starting valves and push rods. Top Overhaul is carried out when the working hours of the diesel engine have worked with around 6,000 hours of work. Major Overhaul maintenance, which includes inspection, maintenance and inspection carried out on all Top Overhaul works and on the piston, connecting rod, piston ring, seated metal and road metal. Major Overhaul maintenance is carried out when the diesel engine has 12,000 working hours according to the Diesel Engine Intruction Book. In the cylinder liner often occurs damage or looseness which is commonly referred to as abrasion, erosion and corrosion. Because of that the cylinder liner requires maintenance and measurement using an inside micrometer tool. From the results of the measurements and maintenance on the cylinder liner, the calculation of the consistency, taper and wear was obtained, to find out the specifications or exceed the limits specified in the Main Engine Intruction Book on the ship.

Keywords: Maintenance, Cylinder Liner, Piston, Overhaul, Diesel Engine 


\section{Pendahuluan}

Diesel Engine adalah suatu peralatan mesin yang memiliki berbagai unit atau suatu sistem pendukung yang berfungsi menghasilkan tenaga daya dorong kapal, sehingga kapal mampu dioperasikan maju atau mundur [1]. Dengan melihat fungsi dari diesel engine dikapal maka kita sebagai teknisi dan Crew kapal yang mengetahui pentingnya mesin harus mengetahui komponenkomponen penunjang kinerja diesel engine. Dengan mengetahui komponen-komponen yang ada kita juga harus mengetahui perawatan dan mampu melakukan pengukuran setiap komponen agar kinerja diesel engine tidak mengalami kendala yang megakibatkan performa mesin menurun. Sedang komponen penunjang kerja diesel engine adalah seperti cylinder liner dan piston, karena komponen cylinder liner dan piston menentukan besar volume silinder dan kinerja diesel engine.

Cylinder liner adalah salah satu bagian dari beberapa bagian komponen peralatan yang terdapat pada blok mesin. Salah satu fungsi dari cylinder liner adalah berfungsi untuk melindungi bagian dalam cylinder block dari gesekan ring piston [2]. Sepintas Cylinder liner ini bentuknya seperti tabung dimana proses pembuatannya menggunakan proses horizontal centrifugal casting. Horizontal Centrifugal casting merupakan proses pengecoran dengan cara menuangkan logam cair ke dalam cetakan yang berputar.

Pada bagian Cylinder liner yang sudah digunakan sering dijumpai kerusakan atau kelonggaran yang sering disebut dengan abrasi, erosi dan korosi [3]. Maka dalam cylinder liner dan piston harus ada perawatan dan pengukuran dengan mempergunakan alat inside micrometer. Dari hasil pengukuran dan perawatan pada cylinder liner dan piston bisa mendapat perhitungan keovalan, ketirusan dan juga keausan, untuk mengetahui spesifikasi atau melampui limit yang sudah ditentukan dalam Diesel Engine Intruction Book yang terdapat diatas kapal

Kelayakan komponen dapat diihat dan diketahui dengan beberapa macam cara apakah masih layak atau tidaknya suatu komponenkomponen diesel engine untuk dipergunakan atau tidak, untuk kelancaran suatu diesel engine agar tidak mengalami kerusakan yang signifikan [4]. Pada penelitian ini membahas tentang pengukuran cylinder liner dan piston dalam pelaksanan overhaul sesuai dengan jam kerja untuk mengetahui kelayakan komponen didalam diesel engine. Pasa setiap pelaksanaan dikapal suatu mesin wajib melakukan perawatan rutin untuk menegtahui kondisi suatu mesin layak tidaknya untuk pemakainnya atau wajib melakukan suatu overhaul pada diesel engine. Bila diesel engine wajib untuk menerima atau mengalami overhaul dikarenakan batas jam kerja yang sudah ditentukan, maka operator wajib melakukannya. Setelah melakukan overhaul maka kita harus malakukan pekerjaan pengukuran atau pengecekan komponen-komponen diesel engine.

Mesin yang bekerja di ruang silinder ditutup dengan piston yang berfungsi meneruskan ke poros, dan menghasilkan daya oleh pembakaran bahan bakar [5]. Piston berfungsi sebagai penekan udara yang masuk dan juga sebagai penerima tekanan hasil pembakaran ruang bakar silinder liner. Komponen mesin ini sendiri dipegang oleh stang piston yang mendapatkan gerakan naik-turun dari gerakan berputar crankshaft. Sementara itu untuk fungsi utama piston adalah menerima tekanan pembakaran dan meneruskan tekanan pembakaran dalam silinder menuju ke crankshaft melalui piston rod/connecting rod.

Tujuan piston dalam silinder adalah mengubah volume dari isi silinder, perubahan volume dapat diakibatkan karena piston mendapat tekanan lebih dari isi silinder atau sebaliknya piston menekan dinding silinder [6]. Piston yang menerima tekanan dari fluida dan akan mengubah tekanan tersebut menjadi gaya (linear). Serta membuka-tutup jalur aliran. Berdasarkan fungsi tersebut, maka piston harus terpasang dengan rapat dalam silinder. Satu atau beberapa ring (cincin) dipasang pada piston agar sangat rapat dengan silinder. Pada silinder dengan temperatur kerja menengah ke atas, bahan ring terbuat dari logam, disebut dengan ring piston (piston ring). Sedangkan pada silinder dengan temperatur kerja rendah, umumnya bahan ring terbuat dari karet, disebut dengan ring sil (seal ring).

Pekerjaan didalam overhaul sudah mempunyai buku catatan harian sebagai panduan pelaksanaan [7]. Perbaikan bagian yang bergerak adalah perbaikan yang meliputi bagian Top Overhaul dari motor Diesel, dan semua bagian mesin yang bergerak melakukan langkah-usaha. Dilanjutkan Major Overhaul dilaksanakan pada saat motor Diesel sudah bekerja selama antara 6.000 Jam, yang meliputi pemeriksaan, perawatan dan perbaikan pada. Seluruh perbaikan yang dikerjakan Top Overhaul pada waktu mesin diesel 
melaksanakan jam kerja 12000 jam Diesel Engine Intruction Book.

\section{Metodologi Penelitian}

Pada penelitian yang dilakukan dengan cara survei dikapal yang sedang melakukan dokc dengan pekerjaan overhaul mesin diesel. Dilakukan dengan 2 kapal yang berbeda dan perusahaan yang berbeda untuk mendapat data-data overhaul mesin diesel. Dengan kapal pertama memakai mesin diesel merk NIIGATA type GMME 31 EZ sedang kapal kedua memakai mesin diesel merk NIIGATA type 28 ATE. Berdasarkan data yang diambil sebagai bahan untuk mengolah data untuk mendapat hasil dalam jurnal. Metode penelitian yang dilakukan dengan cara adalah :

a. Mengumpulkan data-data hasil overhaul diesel engine pada cylinder dan piston

b. Mengumpulkan data-data perawatan yang dilakukan pada diesel engine

c. Survei kelapangan untuk mengetahui bagaimana cara pengukuran kelonggaran pada cylinder liner dan piston

d. Wawancara langsung kepada anak buah kapal yang melakukan kerja overhoul

Objek penelitian menggunakan data-data dari 2 kapal yang melakukan overhaul pada mesin diesel dengan melakukan pengukuran kelonggaran cylinder liner dan piston. Diagram alur penelitian atau survei yang dilakukan untuk mendapat hasil data pada saat overhaul adalah sebagai berikut dapat dilihat berdasarkan pada gambar berikut:

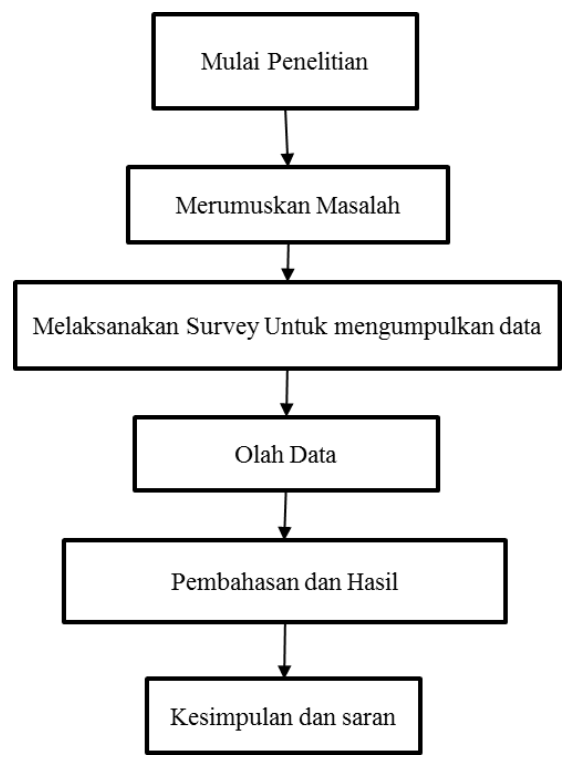

Gambar 1. Rencana alir penelitian

Pada komponen diesel engine diharuskan terdapat pelumasan agar tidak terjadi keausan apalagi pada bagian cylinder liner dikarenakan dilalui oleh cicin torak, sehingga kerusakan atau keausan sering terjadi [8]. Selain itu karena temperatur diatas silinder serta pelumasan yang kurang. Selain perbaikan mesin diesel kapal juga mendapat reparasi dan perawatan, perawatan mesin kapal merupakan salah satu hal yang penting untuk dilakukan. Dengan perawatan yang rutin dan terencana, mesin dapat berjalan dengan optimal karena tidak ada kerusakan-kerusakan yang ada, hal ini sangat menguntungkan karena dapat mengurangi beban kerja pada reparasi dok tahunan. Perawatan kapal meliputi cara pengoperasian mesin. Tata cara ini harus sesuai dengan buku panduan yang dikeluarkan oleh perusahaan pembuat mesin. Metode perawatan yang dilakukan juga harus seuai dengan jam kerja/beban kerja mesin. Harus selalu dilakukan pemeriksaan terlebih dahulu sebelum mengadakan perawatan, pembersihan, ataupun penggantian komponen. Adakalanya, walau pun life time masih lama, namun komponen sudah mulai bermasalah haruslah segera diganti. Karena apabila dibiarkan hal ini akan mempengaruhi kinerja mesin secara seluruhnya dan mengakibatkan kerusakan. Perawatan menjadi sangat penting karena dapat mencegah kerusakan berat pada kapal dan mencegah kemungkinan mesin rusak dan harus diganti. Disesuaikan dengan jumlah jam kerja material dan metode perawatan dengan cara antara lain :

a. Lakukan perawatan, pemeriksaan, pengukuran, perbaikan, atau penggantian material sesuai jam kerja

b. Dari pengecekan fisik, dapat diambil keputusan material yang dirawat, diperbaiki, atau diganti walau jam kerja belum terpenuhi / belum waktunya.

c. Pelaksanaan Perawatan dan Perbaikan, Pembersihan, pemeriksaa, pengukuran, penganalisaan, penggantian material atau pengecekan fisik :

1) Tahap pertama : Top Overhaul yang meliputi material, kepala silinder, penekan katup lengkap, batang pendorong, katup isap dan buang, katup udara berjalan.

2) Tahap Kedua : Major Overhaul, yang meliputi torak dan ring torak, batang torak, poros engkol, poros nok dan lain-lain.

3) Tahap ketiga : General overhaul, yang meliputi kekuatan baut-baut bagian mesin, fondasi, poros engkol, mur dari crank pin bearing, gear box dengan semua roda giginya dan peralatan pengaman yang menempel dibadan mesin. 
Salah satu bagian permesinan yang sangat penting adalah Kepala silender, dimana fungsi pertama dari kepala silinder adalah untuk menahan tekanan dan ledakan hasil usaha dari setiap silinder mesin. Selanjutnya Fungsi kedua adalah untuk menempatkan seluruh bagian / peralatan penting lainya seperti tertuliis pada pekerjaan Top Overhaul tersebut. Penekan katup lengkap ini merupakan bagian kecil yang paling banyak bergerak melayani pembukaan dan penutupan katup buang dan katup masuk ,sehingga gesekan yang diterimanya juga sangat banyak dan menimbulkan keausan-keausan yang tidak merata, perawatanya dengan sistem pelumasan yang cukup dan lancar [7]. Batang pendorong penekan katup periksa jangan sampai batang / tuas tidak lurus yang disebabkan pernah terjadi penyekatan kelonggaran katup atau disebut Valves clearance terlalu sempit / rapat, sehingga akibat dari kelonggaran penyetelan katup batang pendorong Rocker Arm sehingga menyebabkan tertekan sampai bengkok. Apabila sudah bengkok, maka penyetelan katup tidak bisa akurat lagi. Katup buang lengkap, keterlambatan melaksanakan perawatan dan perbaikan katup buang lengkap dapat mengakibatakan kerusakan bagian-bagian internal lainya. Maka diharapkan setiap masinis kapal yang melakukan pemeriksaan harus benarbenar memahami fungsi katup buang lengkap pada sebuah mesin diesel dengan sistem pembilasan memanjang .

Pengukuran Torak, Pengukuran dan pemeriksaan pada diameter torak antara posisi depan-belakang atau pada posisi A-A, dari bagian atas sampai bagian bawah minimal 5 posisi, diperbandingkan dengan diameter torak standar, berapa berkurangnya atau keausan torak tersebut. Pengukuran diameter torak atau piston antara posisi kiri-kanan atau B - B pada posisi, kemudian membandingkan dengan diameter standar torak standar, bertambahnya diameter dan keausan torak tersebut. Tujuan dari pengukuran ini adalah untuk mengetahui seberapa jauh diameter torak atau badan torak yang sudah mengalami keausan akibat gesekan dengan dinding silinder atau cylinder liner dan juga adanya kemungkinan keausan badan torak yang tidak merata. Pada posisi pengukuran A-A atau bagian Port-starboard side ini akan lebih jelas menunjukan tingkat Ovalitet badan torak, apabila diketemukan ring torak yang sudah menipis, karena gerakan tekanan balik pada badan torak yang menerima tenaga pembakaran akan bergerak kearah kanan atau starboard dan langsung bersentuhan dengan dinding silinder, akibatnya badan torak dan dinding silinder keduanya akan mengalami keausan. Pengukuran bagian Ring-torak, pengukuran tebal/lebarnya bagian Ring-torak lama dan tebal/lebar bagian Ring-torak baru, kemudian dibandingkan untuk mengetahui seberapa tingkat keausan Ring-torak

\section{Hasil dan Pembahasan}

Temuan dari hasil penelitian terdahulu dapat dijadikan data pendukung dalam membahas hasil penelitian. Referensi jurnal yang penulis dapat antara lain:

Tabel 1. Referensi Jurnal

\begin{tabular}{|c|c|c|}
\hline $\begin{array}{l}\text { Nama } \\
\text { Peneliti }\end{array}$ & $\begin{array}{c}\text { Judul } \\
\text { Penelitian }\end{array}$ & Tujuan \\
\hline \multirow{11}{*}{$\begin{array}{l}\text { AR. } \\
\text { Ismail.20 } \\
16\end{array}$} & Predictive & Mengetahui \\
\hline & Maintenance & pengaruh \\
\hline & (PdM) Dengan & Predictive \\
\hline & Sistem Major & Maintenance \\
\hline & Overhaul Pada & $(\mathrm{PdM})$ dengan \\
\hline & Mesin Diesel & sistem \\
\hline & Mirrless & Overhaul pada \\
\hline & Blackstone & Mesin \\
\hline & ELS 16 MK 2 & Mirrless \\
\hline & Di $\quad$ PLTD & Blackstone ELS \\
\hline & Poasia & $16 \mathrm{MK} 2$ \\
\hline Persamaan & $\begin{array}{l}\text { Proses } \quad p \\
\text { pemeriksaan } m\end{array}$ & $\begin{array}{l}\text { awatan dan } \\
\text { in }\end{array}$ \\
\hline Perbedaan & $\begin{array}{lr}\text { Hanya } & \text { mem } \\
\text { antara } & \text { predic }\end{array}$ & $\begin{array}{l}\text { has hubungan } \\
\text { ve maintenance }\end{array}$ \\
\hline & dan Major C & erhaul terhadap \\
\hline & $\begin{array}{l}\text { kemampuan } \\
\text { mesin }\end{array}$ & erja dan umur \\
\hline
\end{tabular}

Tabel 2. Referensi Jurnal

\begin{tabular}{lll}
\hline \multicolumn{1}{c}{ Nama } & \multicolumn{1}{c}{ Judul } & \multicolumn{1}{c}{ Tujuan } \\
Peneliti & Penelitian & \multicolumn{1}{c}{ Menyelidiki } \\
2018 & Pengaruh & dari \\
& Posisi & $\begin{array}{l}\text { dampak } \\
\text { pembebanan }\end{array}$ \\
& Cylinder & $\begin{array}{l}\text { Lendi. } \\
\text { tersebut yang tentu }\end{array}$ \\
& Terhadap & berpengaruh \\
& Tingkat & terhadap tingkat \\
& Keausan & keausan pada \\
& Crank & crankshaft \\
& Shaft Bore & boreconnecting \\
& Padacon & rod yang \\
& Necting & difokuskan pada \\
& Rod & engine dengan \\
& Engine & cylinder banyak \\
& $3500 \quad$ & dengandiesel \\
& Series & engine yang \\
& Caterpilla & diaplikasikan \\
& & pada generator
\end{tabular}


Persamaan Pengukuran bagian mesin

Perbedaan pengukuran hanya pada bagian crankshaft mesin

Setelah melakukan kegiatan penelitian ini untuk mengumpulkan data-data yang diperlukan dalam penelitian ini. Penulis mendapatkan 2 data dari diesel engine yang telah dioverhaul dengan data pada setiap kapal yang dilakukan survei yang dapat diperhatikan pada tabel 1 dibawah ini.

Tabel 3. Data-data hasil survei

\begin{tabular}{ccccc}
\hline No & Power & $\begin{array}{c}\text { Jam } \\
\text { putaran }\end{array}$ & $\begin{array}{c}\text { Standard } \\
\varnothing \mathbf{~ m m}\end{array}$ & $\begin{array}{c}\text { Limit } \\
\mathbf{m m}\end{array}$ \\
\hline 1 & 2100 & 12000 & $310 \mathrm{~mm}$ & $\pm 1,5 \mathrm{~mm}$ \\
2 & 6750 & 12000 & $400 \mathrm{~mm}$ & $\pm 2 \mathrm{~mm}$ \\
\hline
\end{tabular}
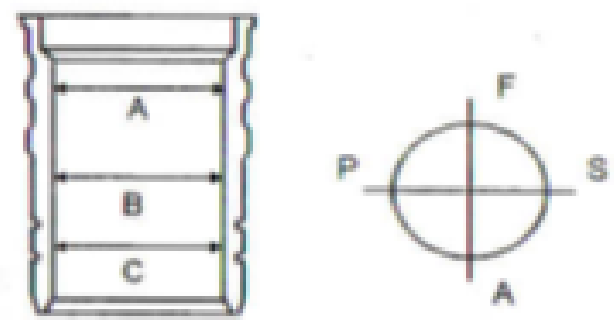

Gambar 2. Cylinder liner
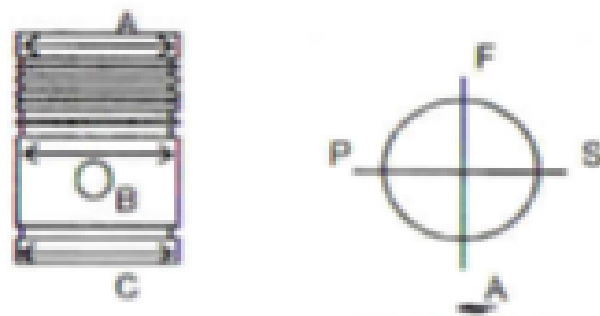

Gambar 3. Piston

Dari gambar 2, dan 3 dapat melakukan pengujian kelonggaran pada cylinder liner dan piston dengan cara pengukurannya adalah :

a. Pengukuran dan pemeriksaan diameter bagian dalam silinder pada Cylinder liner pada bagian depan belakang (Fore-After) pada posisi dari bagian atas sampai kebawah minimal 5 posisi, kemudian diperbandingkan dengan diameter standar pabrikan, berapa kelebihan atau plus dan keausanya.

b. Maksud dari pengukuran ini adalah untuk mengetahui seberapa jauh diameter dinding silinder Cylinder liner yang sudah mengalami keausan akibat dari gesekan dengan torak badan torak dan juga adanya kemungkinan keausan dinding silinder yang tidak merata .

c. Pengukuran diameter pada bagian dalam silinder Cylinder liner antara kiri dan kanan Port-starboard pada posisi dari atas sampai kebawah minimal 5 posisi, diperbandingkan diameter standar, berapa kelebihanny plus keausan silinder tersebut.

d. Pada prinsipnya pengukuran bagian dinding silinder kurang lebih sama dengan pengukuran badan torak. demikian juga harus dapat dipastikan bahwa kondisi dinding silinder dalam keadaan masih standar dan tidak ada yang tergerus/aus atau membentuk kondisi oval yang dapat mengakibatkan lolosnya udara pada saat proses kompresi dan gas pembakaran didalam silinder lolos menerobos keruang engkol dan seterusnya dapat mengakibatkan terjadinya kebakaran/ledakan .

e. Seluruh dinding selinder harus dipastikan tidak ada yang tergores yang dapat membentuk alur dari bagian atas atau TMA sampai kebawah atau TMB, apabila terdapat goresan/alur walaupun masih kecil tetapi arahnya memanjang dari atas sampai kebawah, maka lebh baik segera dilakukan penggantian selinder baru. Kondisi ini dapat mengakibatkan lolosnya udara kompresi dan gas pembekaran didalam silinder menerobos keruang engkol sehingga dapat mengakibatkan terjadinya kebakaran ataupun ledakan pada crank case.

f. Pastikan seluruh lubang-lubang silinder oil apparat, dapat menggeluarkan minyak pelumas dengan baik, tidak ada yang buntu dengan jalan mengecek Priming Cylinder oil apparat Pump oleh seseorang personil yang melakukan pemeriksaan dan pengukuran diameter silinder. Pemeriksaan percikan minyak pelumasan yang disemprotkan dari dinding silinder tersebut Cylinder oil apparat, hindari mengurangi jumlah tekanan minyak pelumasan silinder tersebut, kecuali sudah melalui perhitungan yang teliti sesuai buku petunjuk dari pabriknya.

Pada tabel 2 setelah dilakukan pengukuran yang dilakukan maka mendapat hasil dari cylinder liner dan piston pada mesin diesel yang memiliki power 2100, dengan putaran $12000 \mathrm{rpm}$, standar $310 \mathrm{~mm} \pm$ dan limitnya $1,5 \mathrm{~mm}$ sebagai berikut : 
Tabel 4. Hasil pengukuran kelonggaran cylinder liner

\begin{tabular}{cccccccc}
\hline Posisi & $\begin{array}{c}\text { Cyl. } \\
\text { No }\end{array}$ & $\mathbf{1}$ & $\mathbf{2}$ & $\mathbf{4}$ & $\mathbf{5}$ & $\mathbf{6}$ \\
& & & & & & \\
\hline A & $\mathrm{P}-\mathrm{S}$ & +70 & +23 & +30 & +85 & +65 \\
& $\mathrm{~F}-\mathrm{A}$ & +60 & +27 & +38 & +60 & +70 \\
& $\mathrm{P}-\mathrm{S}$ & +32 & +24 & +30 & +30 & +25 \\
$\mathbf{B}$ & $\mathrm{F}-\mathrm{A}$ & +39 & +17 & +18 & +35 & +30 \\
& & & & & & & \\
& $\mathrm{P}-\mathrm{S}$ & +25 & +18 & +18 & +30 & +20 \\
$\mathrm{C}$ & & & & & & \\
& $\mathrm{F}-\mathrm{A}$ & +20 & +18 & +18 & +16 & +18 \\
\hline
\end{tabular}

Data pada tabel 3 hasil pengukuran dari cylinder liner dengan diesel engine memiliki power 6750, dengan putaran $12000 \mathrm{rpm}$, standart 400 $\mathrm{mm}$, limit $\pm 2 \mathrm{~mm}$ dapat diketahui berdasarkan tabel dibawah ini antara lain.

Tabel 5. Hasil pengukuran cylinder liner

\begin{tabular}{ccccccc}
\hline Posisi & $\begin{array}{c}\text { Cyl. } \\
\text { No }\end{array}$ & $\mathbf{1}$ & $\mathbf{2}$ & $\mathbf{4}$ & $\mathbf{5}$ & $\mathbf{6}$ \\
& & & & & & \\
\hline A & $\mathrm{P}-\mathrm{S}$ & +70 & +23 & +30 & +85 & +65 \\
& $\mathrm{~F}-\mathrm{A}$ & +60 & +27 & +38 & +60 & +70 \\
& $\mathrm{P}-\mathrm{S}$ & +32 & +24 & +30 & +30 & +25 \\
B & $\mathrm{F}-\mathrm{A}$ & +39 & +17 & +18 & +35 & +30 \\
& & & & & & \\
& $\mathrm{P}-\mathrm{S}$ & +25 & +18 & +18 & +30 & +20 \\
$\mathrm{C}$ & $\mathrm{F}-\mathrm{A}$ & +20 & +18 & +18 & +16 & +18 \\
& & & & & & \\
\hline
\end{tabular}

Setelah mengetahui data pengukuran cylinder liner dapat diketahui dari diagram pada gambar 4 apakah cylinder liner diatas layak dipakai atau harus diganti dengan yang baru agar kinerja diesel engine dapat maksimal sesuai fungsinya.

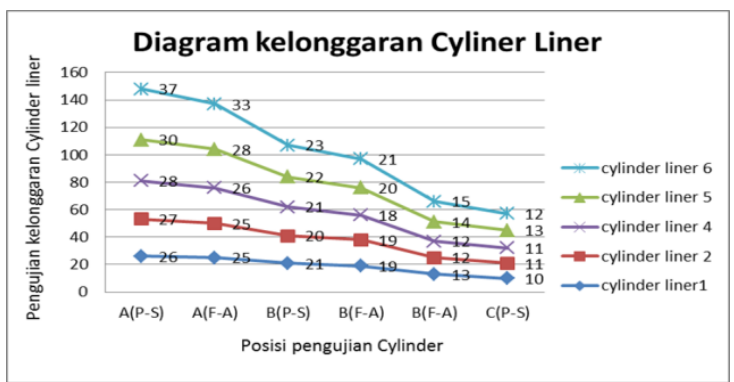

Gambar 4 diagram pengujian pada cylinder liner memiliki power 2100 , jam putaran 12000 , standar $310 \mathrm{~mm}$ dan limitnya $\pm 1,5 \mathrm{~mm}$

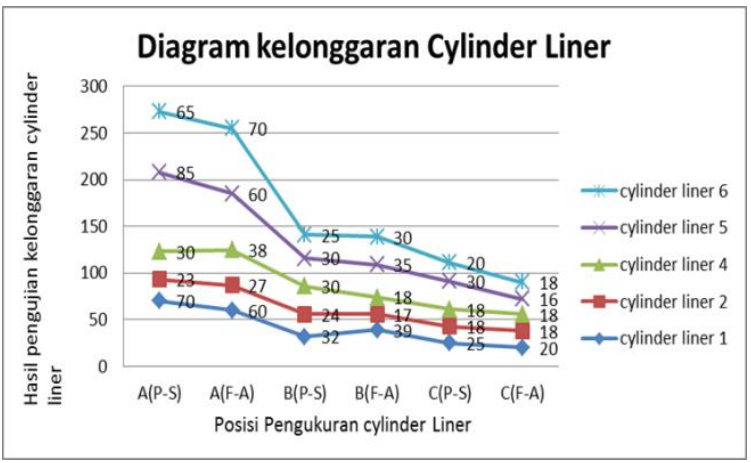

Gambar 5 diagram pengujian pada cylinder liner memiliki power 6750 , jam putaran 12000 , standar $400 \mathrm{~mm}$ dan limitnya $\pm 2 \mathrm{~mm}$

Pada hasil yang dilakukan pada saat pengolahan data mendapatkan kelonggaran pada piston. Dari hasil pengujian kelonggaran pada piston dapat dilihat pada tabel 4 dan 5 dengan pengujian piston memiliki power 2100, dengan putaran $12000 \mathrm{rpm}$, standar $310 \mathrm{~mm}$ dan limitnya \pm $1,5 \mathrm{~mm}$

Tabel 6. Pengujian kelonggaran piston

\begin{tabular}{ccccc}
\hline Posisi & Piston & $\mathbf{1}$ & $\mathbf{5}$ & $\mathbf{6}$ \\
\hline A & P $-\mathrm{S}$ & 308.96 & 308.75 & 308.82 \\
& F $-\mathrm{A}$ & 308.71 & 308.85 & 308.99 \\
B & P $-\mathrm{S}$ & 308.67 & 308.75 & 309.55 \\
& F $-\mathrm{A}$ & 308.69 & 308.84 & 309.62 \\
& C $-\mathrm{S}$ & 308.92 & 308.99 & 309.78 \\
& & & & \\
& F $-\mathrm{A}$ & 308.83 & 309.51 & 309.8 \\
\hline
\end{tabular}


Data berikutnya hasil pengukuran dari piston dengan mesin diesel memiliki power 6750, jam putaran 12000, standart $400 \mathrm{~mm}$, limit $\pm 2 \mathrm{~mm}$ dapat dilihat dari tabel dibawah ini antara lain

Tabel 7. Pengujian kelonggaran Piston

\begin{tabular}{ccccc}
\hline Posisi & Piston & $\mathbf{1}$ & $\mathbf{5}$ & $\mathbf{6}$ \\
\hline A & P - S & 307.97 & 308.98 & 309.76 \\
& F - A & 307.85 & 308.96 & 309.99 \\
B & P - S & 307.88 & 308.88 & 309.92 \\
& F - A & 308.55 & 308.99 & 309.82 \\
C & P - S & 308.57 & 309.1 & 309.88 \\
& F - A & 308.66 & 309.57 & 309.81 \\
\hline
\end{tabular}

Berdasarkan hasil tabel kelonggaran piston diatas dimasukkan kedalam diagram kelonggaran untuk dapat membaca seknifikan kelonggaran pada piston. Yang dapat menentukan hasil pengujian pada kelancaran kinerja mesin diesel.

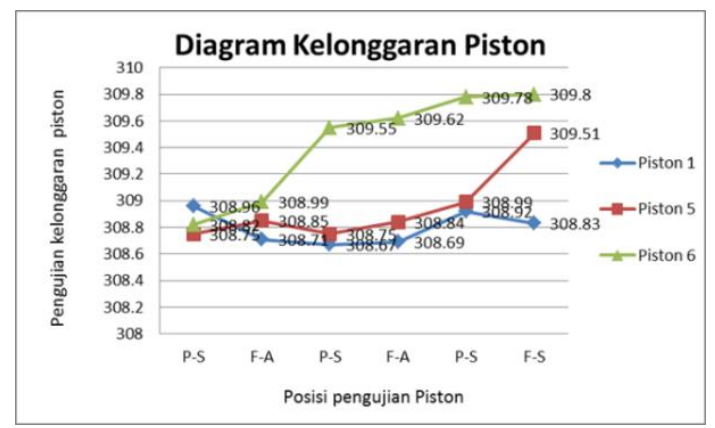

Gambar 6 Diagram pengujian pada piston memiliki power 2100, jam putaran 12000 , standar $310 \mathrm{~mm} \pm$ dan limitnya $1,5 \mathrm{~mm}$

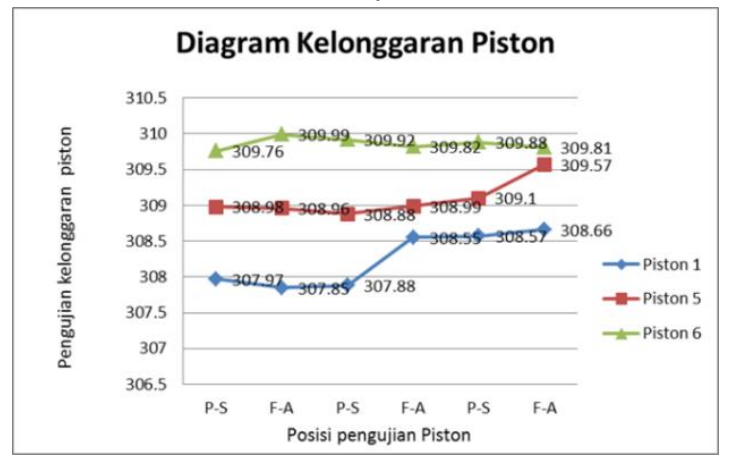

Gambar 7 Diagram pengujian pada piston memiliki power 6750 , jam putaran 12000 , standar $400 \mathrm{~mm} \pm$ dan limitnya $2 \mathrm{~mm}$

Berdasarkan hasil dari data yang telah dilakukan dapat diketahui pada tabel 5 dan grafik
6-7 pengujian pengukuran kelonggaran cylinder liner dan piston mesin diesel. Ternyata terdapat kelonggaran yang dapat mengakibatkan :

1. Lolosnya pembakaran keruang poros engkol, bisa mengakibatkan kebakaran diruang poros engkol.

2. Kinerja mesin tidak sempurna.

3. Tenaga berkurang atau kompresi berkurang

\section{Penutup}

Dari hasil penelitian diatas dapat diberi beberapa kesimpulan tentang pengukuran kelonggaran didalam cylinder liner yaitu kelonggaran pada silinder liner dan piston dapat mengakibatkan kinerja mesin diesel menurun dan tidak terpenuhinya fungsi mesin diesel sebagai mesin penggerak diatas kapal.

Selain perawatan berdasarkan jam kerja pemakaian suatu komponen di mesin juga mempengaruhi suatu kinerja mesin tersebut, serta ada kendala di mesin diesel bila itu perlu maka pemeliharaan harus dimajukan agar kinerja mesin diesel sebagai mesin penggerak kapal tidak berdampak fungsi dan kegunaannya.

Pelumasan berkurang pada komponen bergerak bila mengakibatkan keausan dan kerusakan pada komponen tersebut.

\section{Daftar Pustaka}

[1] Arik H, Komponen Dasar Mesin Induk. Jakarta, 2001.

[2] E. Karyanto, teknik motor diesel. 1993.

[3] Kirono S \& Julianto A, "Analisa Sifat Karakteristik Blok Silinder Liner Bahan Aluminium Silikon," J. Tek. Mesin. Univ. Muhammadiyah Jakarta, 2014.

[4] Priambodo Bambang, Operasi Dan Pemeliharaan Mesin Diesel. Jakarta: Erlangga, 1995.

[5] Motor Diesel Putaran Tinggi, Arismunandar W, Koichi Tsuda. Jakarta, 1993.

[6] Hamid A, "Pengaruh Variasi Volume Silinder (Stroke Up) Dan Variasi Perbandingan Kompresi Terhadap Unjuk Kerja Motor Bensin 4 Langkah. Tugas Akhir Teknik Mesin," Univ. Muhammadiyah Jember, 2014.

[7] Punder, CC Marine Diesel Engine ,Fifth Edition 1977. London, 1977.

[8] Jusak J.H, Perawatan Dan Perbaikan Mesin. Jakarta, 2008. 